\title{
The Conundrum of Clinical Practice Guidelines
}

\author{
Clarence Chant
}

Olinis

inical practice guidelines (CPGs) have been defined by the Institute of Medicine as "systematically developed statements to assist practitioner and patient decisions about appropriate health care for specific clinical circumstances". ${ }^{1}$ The purported benefits of CPGs include improving patient outcomes, standardizing practice by ensuring a certain minimal level of care and discouraging non-evidence-based care, improving consistency and efficiency, highlighting knowledge gaps, stimulating professional discussions, and lowering the cost of care. ${ }^{2}$ However, whether such benefits are realized in actual practice is not clearly documented in the literature. Notwithstanding these potential benefits, implementation of CPGs is a complex and labour-intensive process, and a recent large-scale cluster randomized controlled trial found that multifaceted and comprehensive knowledge translation interventions reaching up to $96 \%$ of the targeted audience in a variety of intensive care units resulted in an increase of only $8 \%$ over 2 years in concordance with a set of evidence-based guideline recommendations for ventilator-associated pneumonia. ${ }^{3}$ At the same time, clinicians have voiced several concerns about CPGs, including poor uptake of guidelines by practitioners, their potential to replace clinical judgment and to impede teaching and curiosity, and their inappropriate use for legal and insurance coverage purposes.

In this issue of the Canadian Journal of Hospital Pharmacy $(C J H P)$, the Point Counterpoint question asks whether clinical practitioners, as part of institutional or accreditation standards, should be required to document rationale when they choose to not adhere to widely accepted clinical practice guidelines. ${ }^{4,5}$ The authors on both sides present many valid lines of reasoning to support their cases. One of the points raised, relating to the degree to which guidelines are actually evidence-based, ${ }^{5}$ merits further discussion. In fact, I believe that the evidentiary basis of guidelines is fundamental, as evidence-based medicine is considered the standard for current practice in the health sciences, and is certainly something we clinical pharmacists all try very hard to instill in our students, fellow practitioners, and even administrators. So, before consideration of whether it should be mandatory for practitioners to cite their rationale for deviation from CPGs, it must be asked whether the guidelines themselves have been developed using rigorous methodologies and thus whether they are valid for use in guiding practice.

The answer is, at least to me, somewhat unexpected. First, numerous validated tools exist for critically appraising CPGs. ${ }^{6}$ One such tool, the AGREE (Appraisal of Guidelines for Research

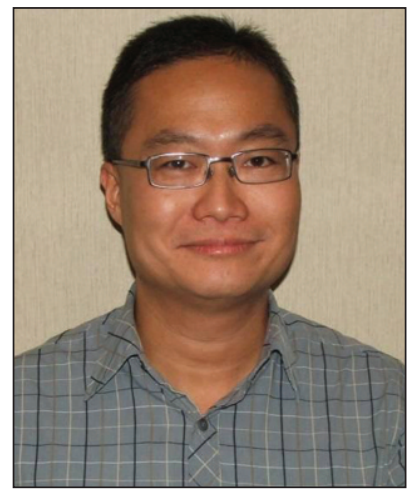
and Evaluation) tool, ${ }^{7}$ is in fact the one used by the Canadian Society of Hospital Pharmacists when the Society is asked to endorse any externally developed CPG. Yet appraisal of CPGs with a validated tool is not routinely part of pharmacy curricula, nor are there any publications focusing on critical appraisal of CPGs similar to what exists for randomized controlled trials (e.g., ACP Journal Club, published by the American College of Physicians). In one study, when CPG appraisal tools were used to critically appraise existing guidelines in intensive care, the mean quality scores were at best $50 \% !^{8}$ The problem is not unique to critical care and has been confirmed in many other areas of medicine. ${ }^{9}$ Fortunately, the quality of CPGs is improving over time. ${ }^{8}$ In addition, other efforts such as the GRADE (Grading of Recommendations Assessment, Development and Evaluation) system for recommendations ${ }^{10}$ and a proposed framework for standardization of reporting ${ }^{11}$ are welcome improvements to increase the quality of CPGs. The GRADE system for recommendations is particularly valuable, given that patients' perspective, quality of life, and cost-effectiveness are all considered in arriving at the final strength of recommendations. This is particularly useful in areas such as geriatrics, where practitioners sometimes need to appropriately deviate from guideline recommendations according to patient-related factors. Finally, the Institute of Medicine has recently published its own standards for developing trustworthy CPGs. ${ }^{12}$

Given the widespread nature of CPGs and their potential to be used in formal documentation with legal implications, as illustrated by the debate in this issue of the CJHP, I would 
encourage all students and pharmacists (or, better yet, any health care provider) to critically appraise CPGs using a validated tool, just as they would a randomized controlled trial, before deciding whether to adopt any of the guideline's recommendations. After all, there are guidelines for guidelines!

\section{References}

1. Field MJ, Lohr KN, editors; Institute of Medicine, Committee to Advise the Public Health Service on Clinical Practice Guidelines. Clinical practice guidelines: directions for a new program. Washington (DC): National Academy Press; 1990.

2. Woolf SH, Grol R, Hutchinson A, Eccles M, Grimshaw J. Clinical guidelines: potential benefits, limitations, and harms of clinical guidelines. BMJ. 1999;318(7182):527-30.

3. SinuffT, Muscedere J, Cook DJ, Dodek PM, Anderson W, Keenan SP, et al.; for Canadian Critical Care Trials Group. Implementation of clinical practice guidelines for ventilator-associated pneumonia: a multicenter prospective study. Crit Care Med 2013;41(1):15-23.

4. El Kassem W, Abdulrahman A, Raghab A, Wilbur K. Should clinical practitioners, as part of institutional or accreditation standards, be required to document their rationale when choosing to not adhere to widely accepted clinical practice guidelines? The "Pro" side. Can J Hosp Pharm. 2013; 66(4):253-4

5. Elgaily DE, Sahal AO, Orabi BA, Ibrahim DA, Wilby KJ. Should clinical practitioners, as part of institutional or accreditation standards, be required to document their rationale when choosing to not adhere to widely accepted clinical practice guidelines? The "Con" side. Can J Hosp Pharm. 2013; 66(4):254-5

6. Vlayen J, Aertgeerts B, Hannes K, Sermeus W, Ramaekers D. A systematic review of appraisal tools for clinical practice guidelines: multiple similarities and one common deficit. Int J Qual Health Care. 2005;17(3):235-42.

7. AGREE Collaboration. Development and validation of an international appraisal instrument for assessing the quality of clinical practice guidelines: the AGREE project. Qual Saf Health Care. 2003;12(1):18-23.
8. Sinuff T, Patel RV, Adhikari NK, Meade MO, Schünemann HJ, Cook DJ. Quality of professional society guidelines and consensus conference statements in critical care. Crit Care Med. 2008;36(4):1049-58.

9. Shaneyfelt TM, Mayo-Smith MF, Rothwangl J. Are guidelines following guidelines? The methodological quality of clinical practice guidelines in the peer-reviewed medical literature. JAMA. 1999;281(10):1900-5.

10. Atkins D, Best D, Briss PA, Eccles M, Falck-Ytter Y, Flottorp S, et al; GRADE Working Group. Grading quality of evidence and strength of recommendations. BMJ. 2004;328(7454):1490.

11. Shiffman RN, Shekelle P, Overhage JM, Slutsky J, Grimshaw J, Deshpande AM. Standardized reporting of clinical practice guidelines: a proposal from the Conference on Guideline Standardization. Ann Intern Med. 2003; 139(6):493-8.

12. Standards for developing trustworthy clinical practice guidelines. Washington (DC): Institute of Medicine of the National Academies; 2011 [cited 2013 May 10]. Available from: www.iom.edu/Reports/2011/Clinical-PracticeGuidelines-We-Can-Trust/Standards.aspx

Clarence Chant, PharmD, BCPS, FCSHP, FCCP, is Director of Pharmacy at St Michael's Hospital, Toronto, Ontario. He is also an Associate Editor with the CJHP.

Competing interests: None declared

Address correspondence to:

Dr Clarence Chant

Pharmacy Department

St Michael's Hospital

30 Bond Street, Room B10007

Toronto ON M5B 1W8

e-mail: CHANTC@smh.ca

\section{ON THE FRONT COVER}

\section{Rockies Sunset Near Hinton, Alberta}

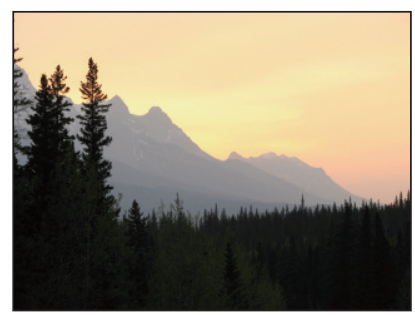

During their May 2011 vacation, CSHP member Natalie Garwah and her family drove across Canada from Ontario to British Columbia, with many stops along the way. One evening, after soaking in the Miette Hotsprings in Jasper Nation- al Park, they were returning to their campground in Hinton, Alberta, when an amazing sunset lit up the sky. The moment was captured with a Canon PowerShot SD880 IS camera. Natalie is a staff pharmacist with Timmins and District Hospital in Timmins, Ontario.

The CJHP would be pleased to consider photographs featuring Canadian scenery taken by CSHP members for use on the front cover of the journal. If you would like to submit a photograph, please send an electronic copy (minimum resolution $300 \mathrm{dpi}$ ) to Colleen Drake at cdrake@cshp.ca. 